\title{
Historical perspectives of The American Association for Thoracic Surgery: John H. Gibbon, Jr (1903-1973)
}

Thomas P. Theruvath, MD, PhD, and John S. Ikonomidis, MD, PhD

\section{BIRTH AND UPBRINGING}

John Heysham Gibbon, Jr, 41st President of The American Association for Thoracic Surgery (AATS), was born on September 29, 1903, as the first son to Marjorie Glendolyn Young Gibbon and John Heysham Gibbon, at their home at 332 South 15th Street, in Philadelphia, Pa. Philadelphia was home to 5 generations of Gibbons. The first American Gibbon had emigrated in 1684 from Wiltshire, England. John H. Gibbon, Jr, came from a long line of physicians, starting back in England, where his great-great-great grandfather had been a London physician. Furthermore, 2 previous generations of Gibbons were graduates of Jefferson Medical College. His father was a respected surgeon and co-chairman of the Department of Surgery at Jefferson and had held many honorable positions, including the presidency of the American Surgical Association. Although his father was his counselor in later years, his mother was more influential during his childhood. Marjorie Gibbon came from the West and was the daughter of a distinguished career officer. She taught him the value of books, and they both indulged in reading during any spare time. She developed his curiosity in literature, philosophy, and poetry, which would be a major interest for the rest of his life. John H. Gibbon, Jr, or Jack, as he was called, had an older sister, Marjorie, and was the older brother to Sam and Robert. As a determined and competitive child, he became an excellent athlete, including tennis, and horse rider, which was fostered on the family's 150 -acre farm.

\section{EDUCATION AND SURGICAL TRAINING}

John Gibbon, Jr, entered Princeton College just before his 16th birthday and matriculated at Jefferson Medical College in 1923 at age 20. Regrets of not following his longing to pursue literature and poetry studies marked the initial years. At one point, he had decided to quit medical school so he could continue his literature studies. However, after consulting with his father, whose ideas and proposals he valued, he decided to continue medical school. He described the initial

\footnotetext{
From the Division of Cardiothoracic Surgery, Medical University of South Carolina, Charlotte, SC.

Disclosures: Authors have nothing to disclose with regard to commercial support. Received for publication Oct 14, 2013; accepted for publication Nov 6, 2013; available ahead of print Dec 12, 2013.

Address for reprints: John S. Ikonomidis, MD, PhD, Division of Cardiothoracic Surgery, Medical University of South Carolina, 25 Courtenay Dr, Suite 7030,

Charleston, SC 29425 (E-mail: ikonomij@musc.edu).

J Thorac Cardiovasc Surg 2014;147:833-6

$0022-5223 / \$ 36.00$

Copyright (c) 2014 by The American Association for Thoracic Surgery

http://dx.doi.org/10.1016/j.jtcvs.2013.11.007
}

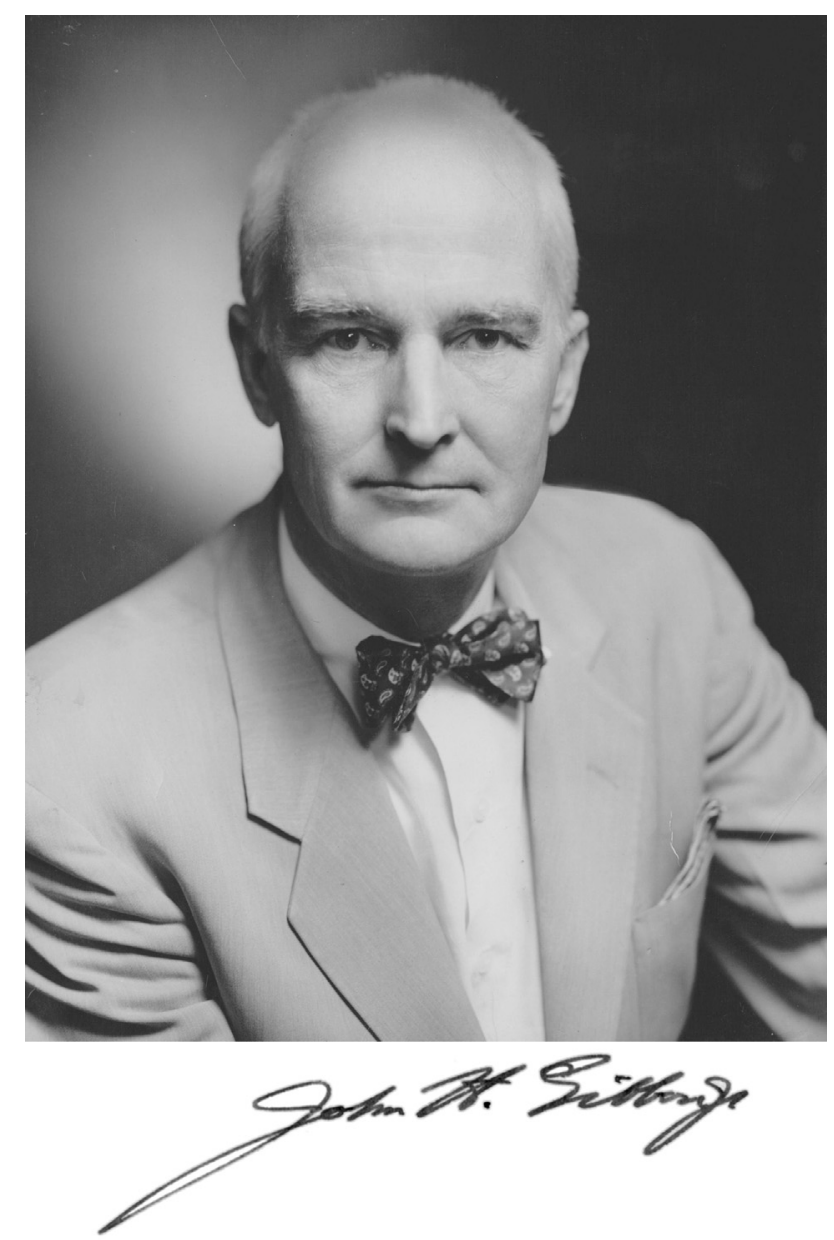

FIGURE 1. Professor John Heysham Gibbon, Jr.

years of medical school as "boring with needless memorization." ${ }^{11}$ Nevertheless, he was a fast and dedicated learner, mastering the final clinical years, and finished medical school in 1927. Without any doubt, this was the correct decision, as the global medical community would witness 27 years later.

After finishing medical school at Jefferson, he continued with a 2-year internship at the Pennsylvania Hospital. His interest in general thoracic surgery led him to contact $\mathrm{Dr}$ Edward Delos Churchill (28th AATS president), who was one of the significant figures in the early development of surgery for lung cancer. He had an active laboratory and later became chief of general surgical services at Massachusetts General Hospital. Gibbon pursued a research fellowship position in Dr Churchill's laboratory and in 1930 
started to perform feline experiments to investigate the mechanical influences of the pericardium on cardiac function and the physiologic changes of an increasing pulmonary artery pressure such as occurs in pulmonary embolism. ${ }^{2,3}$ Together with Mary Hopkinson, Dr Churchill's research assistant, and later Dr Gibbon's wife, they published very efficiently in highly ranked journals such as the Journal of Clinical Investigation and Annals of Surgery. ${ }^{2-4}$

\section{SURGICAL CAREER}

After an internship and clinical fellowships at the Pennsylvania Hospital, Dr Gibbon became a faculty member as a surgeon in 1937 and later an assistant professor of surgery at the University of Pennsylvania in 1945. During World War II, John Gibbon, Jr, volunteered for duty and was in the United States Army from 1942 to 1945 . He served as major and lieutenant colonel on the surgical service for the 52nd Evacuation Hospital in the South Pacific and later at Mayo General Hospital. In 1946, he returned to his alma mater at the Jefferson Medical College, where he quickly ascended to the rank of full professor and in 1956 became the Samuel D. Gross professor of surgery and chairman of the department of surgery (Figure 1). He remained the head of the department and also a consultant surgeon at the Pennsylvania Hospital and Veterans Affairs Hospital in Philadelphia until his retirement in $1967 .{ }^{5}$

\section{CURRICULUM VITAE HIGHLIGHTS}

Although Dr Gibbon will always be known as the inventor of the cardiopulmonary bypass machine, he also made several other clinical contributions. He served on the editorial board of Annals of Surgery from 1947 to 1973 and was its chairman from 1947 to 1957 . He authored the textbook Surgery of the Chest, ${ }^{6}$ which is in its 8th edition and has set the standard as a reference in the field of cardiothoracic surgery. He was a member of the examination committee of the American Board of Surgery from 1953 to 1956 and served as its chairman from 1955 to 1956 . He was president of the American Surgical Association in 1954, the AATS for 1960 to 1961, the Society of Vascular Surgery for 1964 to 1965, and the Society of Clinical Surgery for 1953 to 1954 and was elected to the National Academy of Sciences in 1972. Among his numerous awards was the Albert Lasker Clinical Research Award, which he received in 1968, often referred to as the American Nobel prize. ${ }^{1,7,8}$

\section{ACCOMPLISHMENTS AND CONTRIBUTIONS TO THE FIELD OF CARDIOTHORACIC SURGERY}

Dr Gibbon's pursuit of advancing medicine was fueled by the well-described event in Boston in October of 1930, when a young woman, after an uneventful cholecystectomy, developed severe onset of chest discomfort and difficulties breathing, consistent with acute pulmonary embolism. She was moved to the operating room for constant close observation. It was Dr Gibbon who was given the responsibility to assess her clinically and to document her pulse, respiratory rate, and blood pressure every 15 minutes starting at 3 PM that day. He was ordered to inform Dr Churchill immediately when her vital signs would deteriorate so that an emergent embolectomy could be performed. Dr Gibbon reported that at $8 \mathrm{Am}$ the next day, she had become apneic and was without a measurable blood pressure. Dr Churchill opened her chest, incised the pulmonary artery, removed the blood clot, and placed a side-biting clamp on the pulmonary artery, all within less than 7 minutes. This patient, however, died, just as had most of the patients for whom Dr Friedrich Trendelenburg had described this technique in Leipzig, Germany, 23 years earlier. For Dr Gibbon, it was this event that sparked the idea of a cardiopulmonary bypass machine, which would, 23 years later, advance and revolutionize the entire field of cardiothoracic surgery. He described his thoughts ${ }^{9}$ as follows:

During that long night, watching helplessly the patient struggle for life as her blood became darker and her veins more distended, the idea naturally occurred to me that if it were possible to remove some of the blue blood from the patient's swollen veins, put oxygen into that blood and allow carbon dioxide to escape from it, and then inject continuously the now-red blood back into the patient's arteries, we might have saved her life. We would have bypassed the obstructing embolus and performed part of the work of the patient's heart and lungs outside the body.

During the next 2 decades, he continued his search for a heart-lung substitute, tireless and with utmost perseverance. A fruitful collaboration with IBM Corporation allowed him to develop and assemble a first model of a bypass machine, which was successfully used in canine experiments (Figure 2). ${ }^{10}$ An upgrade of his cardiopulmonary bypass machine allowed increased blood flow, allowing its use in humans (Figure 3). On May 6, 1953, at the

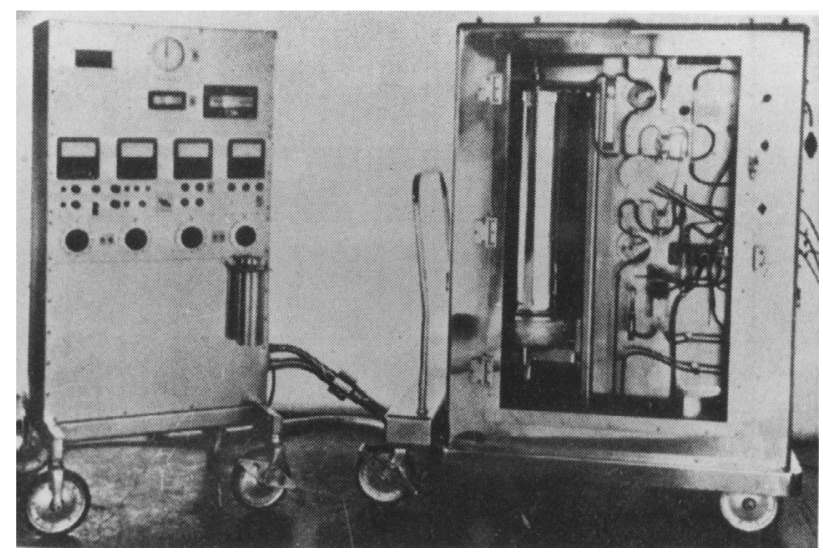

FIGURE 2. Dr Gibbon's first version of the heart-lung machine (IBM I). This machine was used up to 1951 in experimental canine models. 


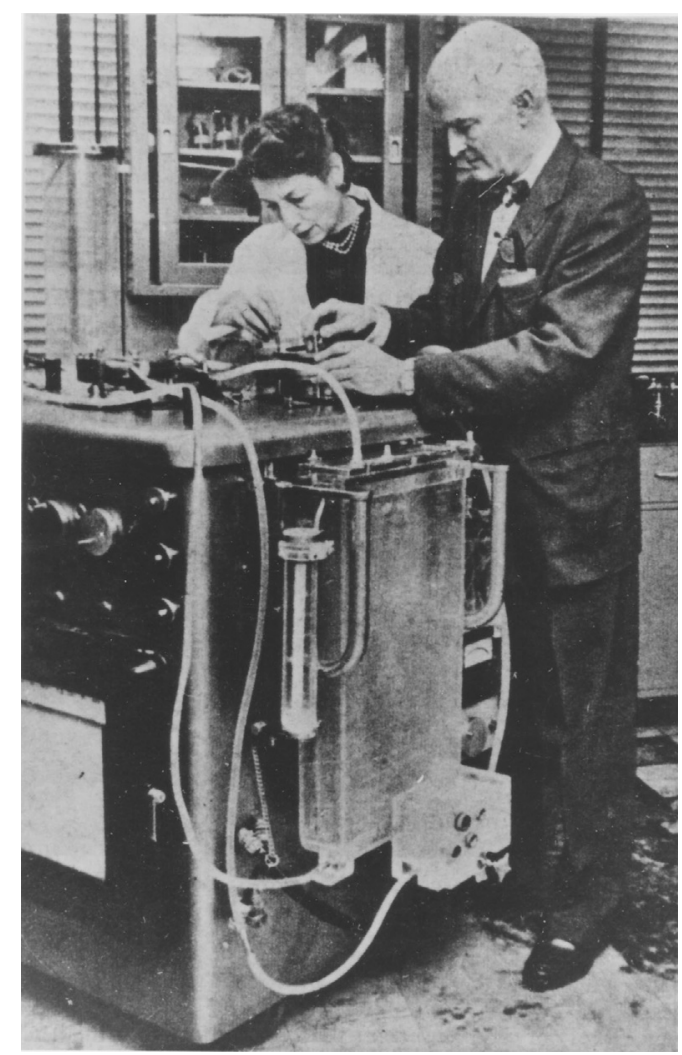

FIGURE 3. Dr Gibbon and his wife Mary ("Maly") Gibbon with the newer version of the heart-lung machine (IBM II). This was the second and more refined model that Dr Gibbon used on his first patients.

Pennsylvania Hospital, the first successful use of Dr Gibbon's heart-lung bypass machine was used on an 18-year-old woman, named Cecilia Bavolek. She had been diagnosed with an atrial septal defect, which had been undiagnosed until then, given the insufficient diagnostic modalities of the previous era. Although her parents had been told of some congenital heart disease, she had remained asymptomatic until she necessitated admission for severe fatigue and hemoptysis. Dr Gibbon operated with Dr Frank Allbritten (who had invented the left ventricular apex vent) and 2 of his residents using his heart-lung machine. ${ }^{11,12}$ By way of a clamshell incision, the defect was repaired primarily. The heart and lung functions were bridged with cannulation of the left subclavian artery and bicaval venous cannulation for 26 minutes (Figure 4). Cecilia Bavolek had an uneventful recovery and was discharged home on postoperative day 13. . $^{8,13}$

Dr Gibbon's creative imagination, which was sparked in 1930 from the inability to help a dying patient, and his dedication and perseverance in designing an efficient heart and lung substitute, led to the landmark operation in 1953. Although other national and international centers were experimenting in an effort to assemble a heart-lung machine for clinical use in the late 1940s and 1950s, it was John

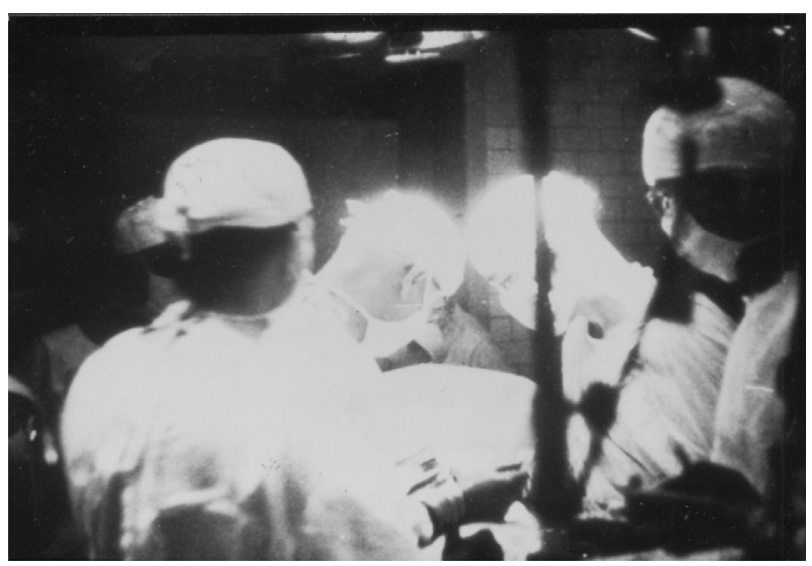

FIGURE 4. May 6, 1953: The Bavolek operation. Drs Gibbon (left) and Frank Allbritten (right) performing the first successful open heart surgery to close an atrial septal defect in Cecilia Bavolek.

Gibbon's work as a physician and scientist in its ultimate definition that led to the first successful and safe conduct of open cardiac surgery. However, both of his subsequent patients whom he operated on a few months later using his heart-lung bypass machine died during the procedure. Deeply disappointed by these failures to rescue these patients, he chose to let additional clinical use of his machine be performed by others in the field. It is hardly surprising that he has been called the "father of extracorporeal circulation." To honor Dr Gibbon at Thomas Jefferson University in Philadelphia, his alma mater, one of the university hospital buildings has been renamed the "Gibbon Building."

\section{SUMMARY OF AATS PRESIDENTIAL ADDRESS}

The presidential address of Dr John H. Gibbon, Jr, "The Road Ahead for Thoracic Surgery," presented at the 41st

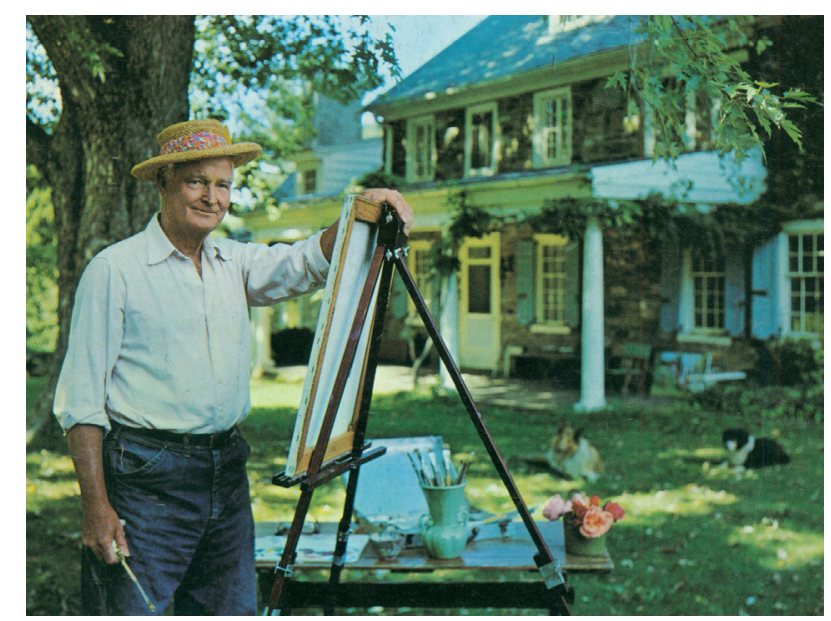

FIGURE 5. Dr Gibbon during his retirement at his family homestead in 1970. 
annual meeting of the AATS, in Philadelphia, April 24 to 26,1961 , was influenced by his extremely successful physician and scientist career in an era when significant contributions to cardiothoracic surgery had climaxed and revolutionized the field. ${ }^{14}$

He started by explaining how the field of thoracic surgery had slowly matured from an embryonic state in 1917, when the AATS was founded, to a youthful state in 1961, and that it still had not attained maturity. He gave examples of the advancements in thoracic, cardiac, and pediatric cardiac surgery, including his own contribution of using his cardiopulmonary bypass machine to perform safe open heart surgery. He delineated how these early advancements were only possible because of concomitant advancements and developments in other fields of medicine, such as the development of heparin, antibiotics, and a better understanding of cardiopulmonary physiology. Dr Gibbon stated that "much remains to be done," specifically, increasing the safety of thoracic operations and understanding the physiology of cardiac ischemia and hypothermia-induced slowing of metabolic demand. The proposed transition of thoracic surgery from its youth in the 1960s to manhood is what Dr Gibbon presented in the second part of his presidential address.

He documented that in an era of funding abundance in which the Department of Health, Education, and Welfare had increased their spending fourfold from 1953 to 1958 and with well-equipped laboratories, the essential requirement was well-trained physician-investigators. He then asked the question of whether enough young medical students and physicians have been properly educated in the methods of scientific education and have engaged in research. Dr Gibbon emphasized that a good researcher needs qualities such as honesty, integrity, passion, patience, persistence, and attention to detail and must be incorruptible. He noted that many with these qualities might have no interest in research, but instead in teaching, and should not be institutionally forced into conducting experimental investigations. As such, he proposed that every academic institution should have positions designed solely for teaching and others solely to conduct research.

He then stated that, during surgical education, at least 1 year should be spent in a laboratory, where the young surgeon in training will, at a minimum, become a critical reader of surgical published studies. After the formal surgical education, "the embryo surgeon" should pursue a second period of research, preferably at a different institution, to give young clinicians and investigators greater experience and the basics of conducting bench research. He emphasized the significance of a good mentor, teacher, and investigator. He finished his presidential address by providing 6 common errors in conducting research and the notion that fewer, but more concentrated, endeavors of the society toward properly motivated and qualified investigators will result in more significant contributions.

\section{PERSONAL LIFE}

Dr John H. Gibbon, Jr, met his wife Mary Hopkinson, or Maly as she was known to most, at the age of 30. Mary was the daughter of Charles Hopkinson, one of America's greatest portraitists. They met as he started his research fellowship in February 1930, in Boston, where Maly was working as Dr Edward D. Churchill's laboratory assistant at the Massachusetts General Hospital. They married on March 14, 1932, and had 4 children, Mary, John, Alice, and Marjorie. Gibbon retired from his chairmanship in 1967 and from then on indulged in poetry, painting, and sports, spending most of his time at the farm (Figure 5). A devastating heart attack took his life on the tennis court on February 5, 1973, at the age of 69.

Figures 1 to 5 have been provided courtesy of the Archives and Special Collections, Thomas Jefferson University, Philadelphia, $\mathrm{Pa}$. The authors would like to thank F. Michael Angelo, MA, University Archivist, Thomas Jefferson University, for his assistance in providing the images.

\section{References}

1. Shumacker HB. A Dream of the Heart. Santa Barbara: Fithian Press; 1999.

2. Gibbon JH, Churchill ED. The mechanical influence of the pericardium upon cardiac function. J Clin Invest. 1931;10:405-22.

3. Gibbon JH, Hopkinson M, Churchill ED. Changes in the circulation produced by gradual occlusion of the pulmonary artery. J Clin Invest. 1932;11:543-53.

4. Gibbon JH, Churchill ED. The physiology of massive pulmonary embolism: an experimental study of the changes produced by obstruction to the flow of blood through the pulmonary artery and its lobar branches. Ann Surg. 1936;104:811-22.

5. Shumacker HB. John Heysham Gibbon, Jr.: September 29, 1903-February 5, 1973. Biogr Mem Natl Acad Sci. 1982;53:213-47.

6. Gibbon JH. Surgery of the Chest. Philadelphia: WB Saunders; 1962.

7. Bing R. John H. Gibbon, Jr. Cardiopulmonary bypass—-triumph of perseverance and character. Clin Cardiol. 1994;17:456-7.

8. Cohn LH. Fifty years of open-heart surgery. Circulation. 2003;107:2168-70.

9. Gibbon JH Jr. The development of the heart-lung apparatus. Rev Surg. 1970;27: 231-44.

10. Miller BJ, Gibbon JH Jr, Greco VF, Smith BA, Cohn CH, Allbritten FF Jr. The production and repair of interatrial septal defects under direct vision with the assistance of an extracorporeal pump-oxygenator circuit. J Thorac Surg. 1953; 26:598-616; discussion 31-2.

11. Miller BJ, Gibbon JH Jr, Greco VF, Cohn CH, Allbritten FF Jr. The use of a vent for the left ventricle as a means of avoiding air embolism to the systemic circulation during open cardiotomy with the maintenance of the cardiorespiratory function of animals by a pump oxygenator. Surg Forum. $1953 ; 4: 29-33$.

12. Hedlund KD. A tribute to Frank F. Allbritten, Jr.: origin of the left ventricular vent during the early years of open-heart surgery with the Gibbon heart-lung machine. Tex Heart Inst J. 2001;28:292-6.

13. Gibbon JH Jr. Application of a mechanical heart and lung apparatus to cardiac surgery. Minn Med. 1954;37:171-85.

14. Gibbon JH Jr. The road ahead for thoracic surgery. J Thorac Cardiovasc Surg. 1961;42:141-9. 